\title{
LA LIEBRE, DE CÉSAR AIRA O UNA SESGADA SÁTIRA DE LA NACIÓN
}

\author{
Silvana Mandolessi (K. U. Leuven)
}

Cet article examine la possibilité de lire La liebre, un roman de l'auteur argentin César Aira, comme une satire de l'idée de nation. Au début, la notion de satire comme un genre qui implique la défense d'une position idéologique et une attitude critique vis-à-vis de son objet, contraste avec les paramètres de lecture que l'œuvre d'Aira a suscités. Toutefois, La liebre peut être lu à la lumière d'un certain nombre de textes satiriques classiques dont l'objet est aussi l'ambiguïté ou la fiction inhérentes à l'idée de nation. En ce sens, l'article réévaluera la validité d'une lecture «satirique » pour la littérature contemporaine.

Plantear una lectura satírica de La liebre, novela de César Aira publicada en 1991 es, al menos, una hipótesis arriesgada. No voy, por lo tanto, a afirmar que este texto es una sátira, para leer desde allí sus estrategias sino que desearía suspender la afirmación -“ $L a$ liebre es una sátira”- para transformarla en una pregunta: ¿puede esta novela ser leída no desde una definición restrictiva del género, pero al menos desde un concepto más amplio, lo que Charles Knight llama "the satiric frame of mind"? Formular esta pregunta permite no sólo indagar algunas particularidades del texto, sino también algunas definiciones sobre la sátira, que en principio aparece hoy, en la época de la post-literatura, como un género ligeramente anacrónico.

La liebre, como señala Sandra Contreras "vuelve a contar cuentos ya contados". En el Siglo XIX un naturalista inglés llamado Clarke emprende un viaje por el desierto argentino en busca del ejemplar singular de una liebre: la liebre legiberiana. Clarke no se interna sólo en el desierto: lo acompañan Gauna, un gaucho que le sirve de guía y un joven aristócrata, Alzaga Prior, en calidad de aprendiz de acuarelista. Durante el transcurso de la novela el grupo se ve involucrado en diversos conflictos que tienen a la Confederación Mapuche como 
protagonista: desde una participación lateral se involucrarán progresivamente en los enfrentamientos de las diversas tribus, conociendo a los indios en sus maneras sociales, su organización política y sus particulares nociones lingüísticas.

Como la crítica lo ha señalado, La Liebre es una reescritura transparente de algunos de los textos fundamentales de la tradición argentina: el naturalista inglés, Clarke, que emprende un viaje al desierto, al que observa desde el marco particular de una mirada civilizada remite a Journal and Remarks de Charles Darwin, e indirectamente a la extensa tradición de viajeros ingleses que recorren la Patagonia en el siglo XIX (en el texto Clarke es, además, cuñado de Darwin). La idea de una excursión al desierto o una excursión a sus habitantes - los indios reescribe Una excursión a los indios ranqueles (1870), texto clásico de Lucio V. Mansilla, mientras que la genealogía indígena planteada en la novela remite a Callvucurá: la dinastía de los Piedra (1884), de Estanislao Zeballos. Como señala Florencia Garramuño, (Garramuño, 1998: 150) los textos de Mansilla y Zeballos encarnan posiciones opuestas respecto a lo que en el siglo XIX se llamó "el problema del indio" en la política argentina: ¿podían o debían ser los indios incorporados al proyecto de constitución de la Nación? ¿o era su exterminio, en cambio, la mejor solución a ese "problema"? Este debate alrededor de la dicotomía civilización/barbarie es retomado entonces en La liebre, pero significativamente despojado de su carga ideológica. La novela de Aira coloca su historia en un espacio y un tiempo claramente definidos: el desierto argentino, el siglo XIX, lo que equivale a un proceso de "historización de la narración". Pero, al mismo tiempo, la novela organiza esos elementos históricos con una "radical ausencia de lógica histórica". Si el tiempo y el espacio en que sucede la travesía de Clarke otorgan a la novela un marco verosímil, la historia misma en que se verá envuelto se revela imposible dentro de ese marco geográfico e histórico que la novela traza. "Esta ausencia de lógica histórica - afirma Garramuño - ubica a la novela en el más claro terreno de lo ficcional, negándose como reescritura a proponer una historia alternativa, oprimida o evitada en el discurso precursor: la novela no se propone como la otra historia marginal que la élite decidió - o no pudo - no contar" (Garramuño, 1998: 152). En efecto, La liebre no puede ser concebida como una historia alternativa a la marginación del otro en la historia argentina, entre otras cosas, porque el otro no existe en la novela.

El inicio del texto pone en escena los grupos culturales característicos del siglo XIX; Clarke representa al inglés naturalista, Gauna al gaucho, Carlos Alzaga Prior al señorito criollo, el cacique Cafulcurá y el resto de los mapuches a los indios. Así, Clarke es un típico inglés quien, al ver en un episodio llorar a Alzaga Prior siente desazón y remordimiento 
"Creía tener ante él un emblema de su propia vida, y lo espantaba. Era el horror de ser inglés, educado, reservado, de no saber llorar en público (ni en privado), de vivir en una burbuja y no sentir las emociones. (Aira, 1991: 70-71). Del otro lado, la figura típica, estereotipada del indio: "la chuza en una mano, las bolas en molinete en la otra, el cuerpo desnudo cubierto de grasa, las mechas al viento, la cara deformada en un grito feroz, el caballo tendido en un galope largo, sin riendas, a la atropellada" (Aira, 1991: 150).

Pero a la vez, estos rasgos fijos son, a lo largo del texto, permanentemente relativizados a través de una perspectiva irónica que combina, en el caso de los indios, por ejemplo, esa crueldad con los razonamientos filosófico- lingüísticos más sutiles. Los indios razonan según un perfecto manual postestructuralista. Un cacique voroga, ante el asombro de Clarke acerca de que eran la única tribu que no adora los astros, explica esa « antinaturalidad » en términos casi deleuzianos:

«Verá usted, señor Clarke. En ese punto hay dos aspectos que considerar. El primero es la relación que mantenemos con la verdad, o más precisamente con el sentido. Que usted nos considere primitivos (no, no se preocupe, que no lo tomo a mal) solo puede derivar del hecho de que no hacemos uso, como ustedes, de un dios, o un monoteísmo, que respalde nuestra significación en general. Los indios nos hallamos, «todavía », en el estadio de la disposición: al signo lo garantiza no su referencia a un sentido, sino su lugar relativo a una red. También es cierto, y aquí creo que está la clave de su perplejidad, que al ser los astros una pura percepción, lo puramente visible sin inminencias de tangibilidad, exigen una puesta en real, si es posible todas las noches. Es el caso paradójico de un imaginario que necesita ser real para dar cauce a todas las imágenes (...) Gauna bostezó aparatosamente » (Aira, 1991: 172).

Los indios son bárbaros pero parecen estar actualizados en las últimas corrientes de teoría literaria, además de comportarse según las más complejas reglas de la cortesía u ostentar una particular predilección por la simulación. El juego ser/parecer se reitera en otros pasajes del texto cuando se refiere a la descripción de los personajes,

« No parecía ingles, pero había ingleses así, que parecían indios, incluso eran prototípicos, eso había notado Rosas, quien por su parte parecía un inglés de los otros, rubio y coloradote. De entrada lo encontró feo aunque con la ventaja de ser pequeño, como un oriental » (Aira, 1998: 17). Coliqueo era "flaco, desgarbado, negro como un africano, con cara de delincuente chino y larguísimas crenchas aclaradas por la manzanilla", Gauna, el gaucho "debía ser medio indio, aunque por la cara amarillenta y arrugada parecía chino".

Pero La liebre ironiza sobre las fábulas de identidad no sólo en una dimensión discursiva sino también narrativa. La ironía verbal utiliza el humor para cuestionar la idea de una identidad que se plantea como homogénea y afirmativa. Las palabras de Rosas al inicio de la novela "No parecía inglés, pero había ingleses así, que parecían indios, incluso eran prototípicos"- 
disuelve la posibilidad de resolver entre ser/parecer, otorgando un sentido contrario al término "prototípico". Por otra parte, la ironía narrativa que se opera al final, demuestra que todos los representantes de los distintos grupos culturales - distintos al menos al inicio de la novela resultan ser parte de una misma familia. Al final se descubre que Clarke es el hijo de Cafulcurá, Cafulcurá y Juana Pitiley los padres de Clarke, Rossanna y Clarke los padres de Carlos e Iñuy, y Gauna el hermano de Juana Pitiley. Todas las diferencias culturales previas - indios, gauchos, criollos e ingleses - se borran reunidas ahora en una misma familia. "En los textos del pasado eran esas diferencias culturales las que trazaban las fronteras de la Nación”, señala Garramuño. Por lo tanto, el borramiento de esas fronteras cuestiona los fundamentos y la validez de esa idea. Además, el modo en que las identidades son demolidas al final de la novela vuelve absurda cualquier postulación de identidad cultural. Ese final melodramático de reencuentros inesperados entre padres e hijos y antiguos amores perdidos ahora recuperados, asocia una novela que inicialmente podía ser leída en relación a los grupos culturales fundantes de la nación Argentina, a la trama de una telenovela, formato en que la identidad está despojada de toda realidad social o cultural. Si la Nación es habitualmente metaforizada como una familia ampliada, la presencia de la familia -pero extraída ahora de un contexto culturalmente considerado inferior, el melodrama, la televisión- satiriza esa metáfora y lo que conlleva como definición de la Nación.

¿Pero es válido usar la palabra «satiriza» en este contexto? ¿Puede La liebre ser leída como un texto satírico? En primer lugar, quizás hay en la figura de Aira como escritor, en la pose que él mismo ha construido, algo del satirista. Una extensa porción de la crítica sobre el género se dedicó, antes que a formas o estrategias textuales, a indagar en la figura del escritor satírico. Puso el acento en la actitud satírica de una persona real, en su voluntad de atacar un objeto determinado como el rasgo distintivo del género (los textos vendrán después y casi como un resultado compulsivo de ese rasgo de personalidad). El título de Leonard Feinberg, The Satirist. His temperament, Motivation and Influence (1963) es claro al respecto. Es cierto que este interés no existe en la crítica contemporánea, pero el género guarda esas huellas de una relación estrecha entre obra y productor. Más que en otros géneros, la figura de autor, y especialmente, su intención consciente y deliberada de producir determinado efecto, se revela en la sátira como parte constitutiva de la obra. El análisis de Feinberg, entre otros, destacan además la ambigüedad intrínseca del satirista: es una personalidad guiada por una voluntad destructiva, por el deseo -siempre excesivo- de ataque, pero nunca lo hará de manera directa: envuelve este deseo en la bruma de la risa, se disfraza como inocente, plantea siempre juegos 
perversos. En este sentido, las dos características del satirista podrían ser aplicadas a la figura de Aira como autor. Por una parte, la crítica ha reiterado la manera en que su proyecto literario representa un ataque - y un ataque despiadado - a los valores literarios institucionalizados. Aira, -o la literatura de Aira-, afirma Graciela Montado «ha borrado la categoría de correción, la de escritura, la de lo bello, la de la utilidad, la de la ética, la del realismo. Y no ha borrado esas categorías para poner en su lugar la crítica sino simplemente para armar otro sistema al margen del binarismo » (Montaldo, 2005: 103). Respecto al ataque hacia la literatura representativa, el mismo Aira afirma en una entrevista: «Para mí, el realismo tiene la gran virtud de poder romperse. El placer de escribir un capítulo realista es destrozarlo de pronto con un perrito que se pone a hablar o cualquier otra cosa. (...) como una pequeña trampa... pequeñas bromitas » (Montaldo, 2005: 104). Para Graciela Villanueva, la ficción airana destruye la lógica de un sentido coherente, o la abandona, para instaurar una contradicción que suspende el sentido del relato sin ningún tipo de mecanismo ulterior que apunte a superar o justificar dicha contradicción. Respecto a la convención realista, Aira aparece nuevamente como su «agresor», como su destructor, especialmente en tanto destructor de sus mediaciones: comentando unas palabras sobre Balzac, Villanueva afirma: «para Aira el cuestionamiento de una convención ha de pasar inevitablemente por el cuestionamiento de su sistema de mediaciones; eso es precisamente lo que hace su literatura con (casi) todas las convenciones institucionalizadas del contexto en el que vive» (Villanueva, 2005: 76).

Esta voluntad «destructiva » no está llevada a cabo, sin embargo, en un tono beligerante. Al contrario, se ha vuelto un lugar común de la crítica sobre Aira que su figura de autor se construye como la del escritor idiota. ${ }^{1}$ « La escritura de César Aira, y su perfil de escritor no menos que su escritura, han venido desacomodando los parámetros de lectura que imperaban en la literatura argentina », afirma Martín Kohan (Kohan, 2005: 79). Su «perfil de escritor » porque lejos de cualquier proyecto serio, Aira se presenta a sí mismo como quien actúa sin darse cuenta, como un infractor inocente, alguien que si ha trasgredido no es por propia voluntad, sino por desconocimiento de las normas. La sonrisa de esa pretendida ingenuidad recuerda mucho a la perversa ambigüedad del satirista.

\footnotetext{
${ }^{1}$ Para un análisis de la figura de autor de Aira como escritor "idiota", ver el excelente artículo de Julio Premat "El idiota de la familia" en Michel Lafon (ed). César Aira, une révolution. Grenoble: Université Stendhal, 2005.
} 
Retornando a la novela, La liebre forma parte, en la obra de Aira, de la serie "darwiniana", textos que reescriben los clásicos ideologemas de los sistemas discursivos argentinos (la pampa, el viaje al desierto, la figura de la cautiva). La lectura habitual privilegia, por lo tanto, las relaciones con esos textos clásicos de la tradición del siglo XIX, sin tener en cuenta otras, no tan evidentes, pero igualmente significativas. En su análisis de Ema, la cautiva (texto que pertenece también a esta serie), Edgardo Dobry refiere en primer lugar a la extensa serie de textos argentinos a que la novela remite. Posteriormente, y siguiendo una línea que Aira mismo sugiere en la contratapa de la novela, devela conexiones con otra serie, la tradición europea del siglo XIX. En primer lugar, el nombre de Ema remite a Madame Bovary, aunque menos que una referencia concreta a la obra maestra de Flaubert, sería, como señala Dobry, una reafirmación de ese cruce de series: "Ema es menos una referencia a la obra maestra de Flaubert que la sugerencia de un cruce entre la serie nacional, inmediatamente evocada por la palabra "cautiva", y otra serie, la de la novela europea del siglo XIX, con algunas derivaciones anteriores y posteriores" (Dobry, 2005: 304). El nombre del personaje no puede dejar de leerse, también, como un homenaje a Emma (1815) de Jane Austen. La comicidad soterrada del personaje estaba ya presente en aquel texto. Considerando este "antecedente", Dobry señala una cita del crítico T.E. Kebel, quien reconocía en Emma "genuine comedy of the highest order". Pero más significativa es la cita de Virginia Woolf, quien califica a Jane Austen, este "antecedente" del texto de Aira con estas palabras: "She is one of the most consistent satirist in the whole literature" ( Dobry, 2005: 305).

La presencia de este texto de Jane Austen no es el único que permite establecer conexiones de esta serie con la tradición satírica. Dobry señala, además, Erewhon, una novela de Samuel Butler publicada en 1872 como un antecedente de la imagen del indio que aparece en Ema, la cautiva. El libro de Butler es significativo en cuanto "se ubica en la insigne línea en la que el libro de viaje - más o menos ficticio - se cruza con el pensamiento utópico, como en Thomas More y en Jonhatan Swift" (2005: 309). Y de hecho, es los Viajes de Gulliver, de Swift, el último antecedente que quisiera rescatar de los textos propuestos por Dobry, como presencias sesgadas - pero productivas - que funcionan en el texto de Aira.

En el capítulo "Satiric nationalism", Charles Knight afirma que "if nations did not exist, satirist would have to invent them" (Knight, 2004: 67). En efecto, como lo demuestra uno de los textos más conocidos del género, la idea de nación ha sido uno de los objetos privilegiados de ataque de la sátira. Travels into Several Remote Nations of the World, - el título original de Gulliver's Travel (Viajes de Gulliver) de Jonhatan Swift - es, como señala 
Knight "the great proto-nationalist satire on nationality" (Knight, 2004: 68). Al igual que otros ejemplos del género, la sátira de Swift concierne a un cuestionamiento de los elementos falsos y las contradicciones presentes en la idea de la Nación. En primer lugar, las sátiras que exploran el nacionalismo cuestionan el fundamento mismo de estas comunidades imaginarias: la manera en que una Nación se concibe a sí misma en relación a otras naciones, es decir, la necesidad de trazar diferencias culturales - de exacerbar y otorgar valor a esas diferencias - como modo de definirse a sí misma. La liebre puede ser leída en esta tradición, ya que uno de los objetos continuamente parodiados son las diferentes identidades que se imaginan para los grupos culturales, tanto al interior de la Nación misma - indios y señoritos porteños - como al exterior - ingleses y aborígenes-. "The work of satiric nationalism is to explore, sharpen, and complicate the image of the Other, or, more disturbingly, to see the satirist's own country as if it, in turn, were the Other" (Knight, 2004: 50). El modo en que el final de La liebre propone ese borramiento de diferencias, el grotesco y el humor de apelar al género telenovelesco para representar el "reencuentro", sugiere algunos de los recursos característicos de la sátira. Por otra parte, el texto de Swift hace hincapié en otro elemento también común al texto de Aira: los textos del pasado como elemento principal de la constitución genética de la Nación. El proceso de imaginar una nación es el proceso de imaginar un pasado significativamente conectado con el presente. Desde el principio es claro que los textos de ese pasado no representan ninguna adecuación a hechos reales. Las naciones requieren "la posesión en común de un rico legado de memorias", pero, como señala Knight, la falsificación de ese pasado juega en esa posesión común un papel preponderante. Esto es clave para el proyecto de muchas de las novelas contemporáneas a la publicación de $L a$ liebre, que vuelven a episodios históricos o a textos del pasado nacional con el objeto de demostrar las falsificaciones a que fue sometido. A partir de allí, proponen una nueva interpretación, un proyecto ideológico o político alternativo. Nada de esto parece interesar en La liebre. En una dimensión de su lectura, la reescritura de los textos fundamentales del pasado nacional impulsa a buscar el sentido del texto en esa dirección, es decir, en la de una deconstrucción de los estereotipos nacionales, en el de una relectura que proponga un nuevo sentido sobre el pasado en su conexión con el presente. Las primeras críticas de La liebre apostaban a esta clave de lectura, aunque nunca del todo seguras o satisfechas, porque un exceso del texto de Aira - un exceso que es bastante claro en el reencuentro final - la desestimaba. Y esto quizás porque al contrario de proponer una relectura del pasado nacional, es decir, una nueva conexión significativa del pasado con el presente, la manipulación a la que son sometidos esos textos en La liebre, establece una ruptura en la relación significativa del 
pasado y el presente. Esos textos que antes producían un sentido, que pueden - o quizás deben - seguir produciendo sentido en la configuración de la Nación son dislocados, desplazados, vueltos pura ficción. En esta operación el texto se relaciona con presupuestos subyacentes en las sátiras sobre la Nación, en tanto más que proyectos de corrección, relecturas o reescrituras, las sátiras "nacionalistas" cuestionan los presupuestos mismos sobre los que la nación construye su sentido. Un recurso privilegiado para mostrar las incongruencias de esta construcción de sentido es precisamente la de desplazar el objeto de representación hacia un escenario exótico, donde la inversión de perspectivas, o el "reino al revés" es preponderante. El refinamiento de los indios, su finura y sofisticación en oposición a la barbarie de Clarke, el inglés, en ciertos momentos del texto, configuran en Aira una inversión cuyo antecedente está ya dibujado en la tradición de las sátiras sobre la Nación. Y el exótico final de reencuentro familiar puede ser también leído como un juego con la idea de familia, en tanto metáfora de la nación. En este sentido, vuelve a aparecer un elemento común en la tradición del género, el que enfrenta - para disolver- dos imágenes opuestas en el interior del concepto de nación. Como señala Knight,

\footnotetext{
"Satire's exploit the nation's double image. On one hand, nations reflect the human sympathies that bind communities together. It is no accident that the nation's most powerful and recurrent analogy is the family. On the other hand, nations are imagined communities artificial constructs political abstractions whose claims to loyalty are paradoxically personal and moral. Satire plays these natural and artificial images against each other; it scrutinizes national claims by shifting the levels on which they are regarded or by revealing the poses of political self-interest masquerading as morality.” (2004: 80)
}

A la luz de estas conexiones, ¿puede entonces La liebre ser leída como una sátira? Habría que discutir brevemente algunas precisiones sobre el género. En primer lugar, se puede adscribir a una definición restrictiva que entiende la sátira como una "ironía militante". La idea de que bajo su crítica subyace un fuerte esquema ideológico o moral que intenta corregir el vicio y fomentar la virtud, la vuelve casi inútil para pensar la literatura contemporánea. Una definición más amplia, en cambio, propone pensar desde "the satiric frame of mind" - un marco de pensamiento satírico - antes que desde un género determinado. Así, se habla de "modo" o "actitud" satíricos más que de una definición esencial del género. Knight afirma en este sentido que la sátira es pre-genérica, no tanto un género en sí mismo sino una posición 
mental que adopta un género para expresar sus ideas como representación. En contra de la definición restrictiva tradicional, además, Knight niega la función intrínsecamente moral de la sátira. "Satire is independent of moral purpose" (Knight, 2004: 5). Su propósito, sugiere, es un cambio en la percepción antes que en el comportamiento. En la misma línea Dustin Griffin argumenta que la principal función de la sátira es la provocación, antes que cualquier instrucción respecto a códigos preestablecidos. En esta ausencia de características intrínsecas que definan a un género, y destruidas sus supuestas pretensiones "correctivas", los dos elementos que Knight conserva como cualidades centrales del marco satírico son "irony of perspective and the parody created by satiric borrowing" [una perspectiva irónica y la parodia creada por los préstamos satíricos] (Knight, 2005: 6). La perspectiva irónica y la parodia creada a través de préstamos o imitaciones formales, sugieren un permanente juego de límites que la sátira vuelve permeables. Considerada desde esta perspectiva, quizás la sátira no sea un género anacrónico para pensar algunos textos contemporáneos, que hacen de esta indecibilidad una característica esencial. Los textos de Aira son, en este sentido, representativos. En los tiempos de la post-literatura, Aira encarna un proyecto radical como destrucción de los valores institucionalizados acerca de lo que se espera sea la "buena" literatura -o simplemente la literatura. La ironía funciona como un juego de demolición de los sistemas y de los monumentos literarios y culturales que de por sí no produce nada y que presupone, para funcionar, un contrincante tácito, un sistema de creencias implícito y antagónico (el que ve en la literatura una carga moral, cultural, progresista, trascendental en algún sentido). El gesto con el que Aira realiza ese proyecto en cada uno de sus textos, es el de la sonrisa sesgada con que Demócrito - como emblema de la mirada satírica - nos mira desde el cuadro de Velásquez: Demócrito señala un pequeño globo terráqueo, parece estar riéndose de él, aunque la invitación cómplice a hacer lo mismo no aleja una sombra de duda en nosotros: la duda de ser, al mismo tiempo, sujetos y objetos de la broma, de que el objeto de esa sonrisa sesgada, como es habitual en la sátira y como Aira nos hace a menudo sentir, seamos en definitiva nosotros mismos.

\section{BIBLIOGRAFÍA}

Aira, César (1991) La liebre. Buenos Aires: Emecé.

Dobry, Edgardo. "Ema en la frontera. Para una genealogía de la perplejidad". Michel Lafon (ed). César Aira, une révolution. Grenoble: Université Stendhal, 2005. 
Garramuño, Florencia. "La liebre, de Cesar Aira, o lo que quedó de la campaña al desierto". Revista de Crítica Literaria Latinoamericana. Año XXIV, 48, 2 semestre de 1998; $149-158$.

Kohan, Martin. Lo más breve de lo breve. Las novelas ínfimas de César Aira". Michel Lafon (ed). César Aira, une révolution. Grenoble: Université Stendhal, 2005.

Knight, Charles. The Literatura of Satire. UK: Cambridge UP, 2004.

Montaldo, Graciela. «Vidas paralelas. La invasión de la literatura ». Michel Lafon (ed). César Aira, une révolution. Grenoble: Université Stendhal, 2005.

Villanueva, Graciela. « Historias suspendidas en el aire. Una reflexión sobre el sentido en la obra de César Aira ». Michel Lafon (ed). César Aira, une révolution. Grenoble: Université Stendhal, 2005. 